
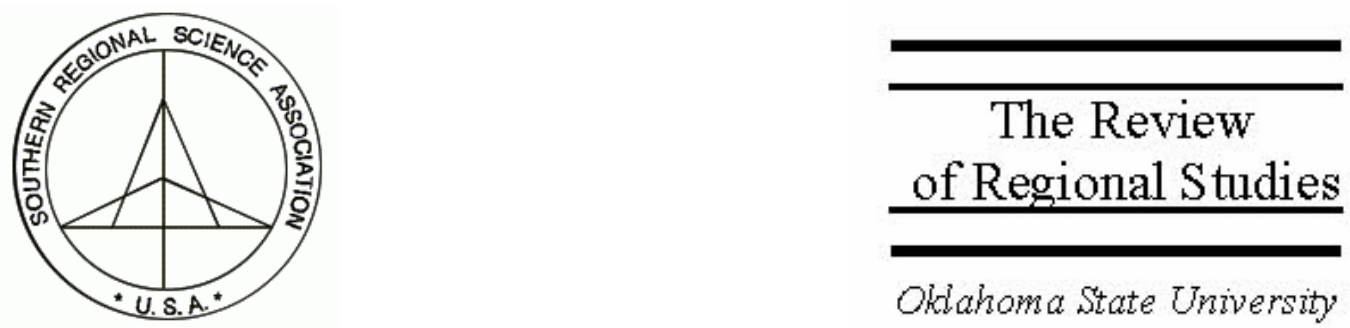

\title{
The Returns to Education in Rural Areas
}

\author{
Stephan J. Goetz \\ Northeast Regional Center for Rural Development, Agricultural and Regional \\ Economics, The Pennsylvania State University and Rural Development Research \\ Consortium, University of California at Berkeley \\ e-mail:sgoetz@psu.edu
}

Anil Rupasingha

American University of Sharjah

P.O. Box 26666

Sharjah, UAE

\begin{abstract}
We compare the returns to human capital in rural areas with those in urban areas, and across the different regions of the US. A key finding is that these returns are considerably lower in rural than in urban areas. Furthermore, failure to correct for spatial dependence bias produces an overestimate of the returns to education at the county-level. We also examine various interactions among the regressors to identify the reasons why the returns to education vary between rural and urban areas.
\end{abstract}

Keywords: Human capital; Mincer equation

JEL classification: I20; J3

The authors thank their discussant, Peter Schaeffer, and two anonymous reviewers for excellent comments. 


\section{INTRODUCTION}

A basic conundrum for many rural communities is that individuals fail to invest in education because the expected returns to such an investment are low compared with the nation as a whole, and the returns are low because there is an insufficient local pool of educated individuals who would be attractive to firms requiring higher levels of skills. ${ }^{1}$ Until now, the differences in these returns - holding constant other pertinent factors have not been measured empirically. A recent study on the returns to higher education in each of the contiguous states as well as the rural areas of the U.S. Northeast, North Central, South, and West found notable differences in the economic returns to high school and college degrees in rural areas within these Census divisions (Goetz and Rupasingha 2003). Concerns over a brain drain due to relatively lower returns to education are not limited to rural areas, however. Policymakers in states ranging from Maine (Trostel 2002) to Pennsylvania (Pennsylvania State Data Center 1999), Iowa (Okamoto 2001), and Idaho (Nelson and Julia-Wise 1999) worry that educated individuals are increasingly leaving in pursuit of more remunerative employment opportunities elsewhere. Finally, Beaulieu and Barfield (2000) and others note the relative degree of underinvestment in human capital throughout the rural U.S. South. This is unexpected to the extent that returns to education tend to be greatest for those who are most disadvantaged (Krueger 1999, Summers and Wolfe 1977).

In this paper we examine the effects of human capital (educational attainment), social capital, and other forms of infrastructure or amenities - including school quality measured by pupil-teacher ratios - on per capita income across U.S. counties over the decade of the 1990s. ${ }^{2}$ We statistically correct for spatial dependence bias in the data and identify the returns to education in rural areas at the county level in each Census region. These returns are compared to the returns to education in metropolitan areas, allowing us to quantify some of the forces behind the brain drain afflicting many rural communities. ${ }^{3}$

Second, we explore why and how the returns to education vary across rural counties by including interaction terms with human capital in the estimation. For example, we examine how different levels of social capital affect the returns to a high school degree in a community by interacting social and human capital measures. We hypothesize that in communities with higher stocks of social capital, the returns to a high school degree are greater.

\footnotetext{
${ }^{1}$ The returns are not low merely because of low demand for educated workers. Returns depend on both supply and demand conditions.

${ }^{2}$ We are, of course, assuming that the quality of the average human capital is the same across counties and that formal education is the primary means by which human capital is generated, along with experience (measured as in other studies using age and age squared terms). It is possible that the optimal combination of skills and knowledge differ among regions. Furthermore, we are not measuring the returns to a degree from a particular institution but, instead, the returns that are earned in a particular county from the average institution of higher education.

3 In this study, the terms "rural" and "urban" are used to describe nonmetropolitan and metropolitan counties.
} 


\section{LITERATURE OVERVIEW AND ESTIMATION ISSUES}

The number of studies relating education or human capital to economic growth has skyrocketed in recent years. Sianesi and van Reenen (2002) and Krueger and Lindahl (2001) provide recent surveys of this work. Goldin and Katz (1999) present a historical analysis of the returns to skills in the U.S. during the twentieth century. The bulk of the education and growth literature, including the widely cited paper by Barro (1991), focuses on cross-country studies, although a sizeable literature on the microeconomics of education (and experience) and wage earnings was spawned by Mincer's (1974) seminal study. Largely unresolved questions at the micro level include whether education truly enhances productivity, as argued in Becker (1964), or whether it merely signals ability, including the ability to work hard and complete tasks, as argued by Spence (1973) (see also Krueger and Lindahl 2001). Sianesi and van Reenen (2002, p. 4) conclude from their literature survey that:

[t]aking the studies as a whole, there is compelling evidence that human capital increases productivity, suggesting that education really is productivity-enhancing rather than just a device that individuals use to signal their level of ability to the employer.

The primary emphasis in the macroeconomic studies has been on relationships across countries. Only relatively recently have researchers examined these relationships at levels of geography within countries, in part to avoid problems that inherently arise in using data from different countries and institutional settings (Rauch 1993; Goetz and $\mathrm{Hu}$ 1996; Rupasingha, Goetz, and Freshwater 2002).

A key modeling issue in analyses conducted at the level of nations is that labor, in theory, is perfectly mobile so that returns to education (and capital) should be equalized over time (Rappaport and Sachs 2001). However, there are a number of reasons why this is not the case, including imperfect information and continuing shocks to state-level labor markets (Goetz and Rupasingha 2003). In some regions, entrenched pockets of poverty limit economic development prospects over time, giving rise to the debate over whether places or people should be developed. Returns to education may also vary over space because individuals willingly accept lower pay in exchange for better scenic amenities as are found, for example, in the Rocky Mountains (Power and Barrett 2001). ${ }^{4}$ To address this concern, it is essential to include as a control a variable measuring natural and other amenities in econometric models of income levels or growth within single nations.

Another important question is that of sorting out causality in these models. In particular, regions that have higher incomes also have a higher demand for and investments in educational attainment (as a "good," human capital has a positive income elasticity of

\footnotetext{
${ }^{4}$ A reviewer suggested that areas with high amenities could be growing more rapidly and have higher wages because of greater demand for labor. However, this ignores the fact that labor supply could also be higher in such areas.
} 
demand). A number of recent studies (including Glaeser 1994) estimate contemporaneous models, with incomes in year $t$ being determined by human capital stocks in the same year. Other studies (e.g., Barro 1991) get around this problem by estimating growth rate models over a period, $\Delta t$, in which initial conditions at the beginning of the period over which growth rates are calculated serve as (exogenous) starting conditions. Yet other studies (e.g., Rupasingha, Goetz, and Freshwater 2002) regress per capita income levels in year $t$ on starting conditions 8 or 10 years earlier $(t-10)$ to address the issue of endogeneity bias. Goetz and Hu (1996) and Ngarambé, Goetz, and Debertin (1998) estimate complete simultaneous equation models to address the endogeneity bias.

Sianesi and van Reenen (2002) distinguish between the literatures addressing the empirical effect of education on the level of income (the "augmented neo-classical approach") as opposed to rate of growth of income in the long run (the so-called "new growth theories" based on Barro-type regression models). At best, issues surrounding the choice of appropriate lags, estimation of growth rates versus levels, and whether to use logs remain unsettled (Krueger and Lindahl 2001, also inter alia, Levine and Renelt 1992). For the OECD countries especially, Sianesi and van Reenen favor the former explanation over the latter, and this is also the one we emphasize in our work described below. ${ }^{5}$

Cheeseman-Day and Newburger (2002, figure 1, p. 2) use Current Population Survey data from 1997-99 to estimate the average annual earnings of workers between 25 and 64 years of age by educational attainment. For full-time, year-round workers, they obtain a synthetic average earnings estimate of $\$ 89,400$ for workers with doctoral degrees, $\$ 109,600$ for professional degree-holders, $\$ 52,200$ for workers with bachelor's degrees, $\$ 30,400$ for high school graduates, and $\$ 24,400$ for those who failed to graduate from high school.

Finally, it is important to point out that most of the literature focuses only on the economic returns to education in the form of per capita incomes or growth rates. (For an exception, see Goetz, Debertin, and Pagoulatos 1998, who examine the effects of educational attainment on the quality of the environment.) In addition, human capital also produces social returns, such as reduced crime rates, reduced dependence on federal welfare programs, greater and more effective civic participation, etc. (Krueger and Lindahl 2001).

\footnotetext{
${ }^{5}$ The specification chosen closely matches one that was originally suggested by Mincer (1974) while reducing, if not eliminating, simultaneity bias. Results reflecting a conventional growth model are available from the authors upon request. As a reviewer pointed out, other authors have estimated rates of growth of employment and population as the proper metrics for county-level growth models incorporating human capital. See, for example, Simon and Nardinelli (2002), Beeson and Dejong (2002), and Rappaport (1999).
} 


\section{MODEL, METHODS, AND DATA}

Our basic model draws on Mincer (1974), who describes the relationship between wages or earnings and educational attainment on the one hand, and experience as proxied by age on the other. We aggregate these individual earnings functions along with other (unearned) sources of income over all county residents to arrive at a representative county worker, using the county-wide average for all residents, and include additional shifters of this function as controls. ${ }^{6}$

\subsection{Selection of Variables (Regressors)}

Per capita income depends on human capital; experience; social capital; infrastructure, or "built capital"; school capital; the relative mix of public and private jobs, including high-tech jobs as a separate variable; agglomeration forces; and natural amenities. The justification for including each of these variables is as follows. As noted earlier, a sizeable literature has emerged around the fact that human capital is widely associated with higher income levels (Dev Bhatta and Lobo 2000; Lucas 1993; Krueger and Lindahl 2001; Sianesi and van Reenan 2002), as is experience. Mincer (1974) was one of the first to conceptualize and document the positive effect of experience on hourly wage earnings. Infrastructure in the form of an interstate highway access ramp is included as a basic form of capital to complement other forms of capital in the regression equation. Social capital, in our conceptualization, reduces transaction costs among economic agents, thereby increasing economic activity and growth. We have shown in earlier work that social capital has an unequivocally positive effect on per capita income growth rates (Rupasingha, Goetz, and Freshwater 2002) but have not explored the effect of interactions between human and social capital.

To measure the labor force structure in each county, we include the number of private and public sector jobs in all jobs. DeVol (1999) reports that two-thirds of income growth in metro areas during the 1990s was accounted for by the high-tech sector, and we include high-tech establishment counts as one factor determining per capita income. Agglomeration in the form of greater population density has been shown to be a key factor in other studies of income growth, due largely to productivity-enhancing effects of spillovers and other forms of interactions, such as enhanced input supplies (Ciccone and Hall 1996; Rauch 1993). Finally, we include natural amenities to control for the relative desirability of each county as a place in which to live. If we failed to include this control, then we would not know whether lower (higher) per capita incomes in the county reflect more (less) desirable living conditions or lower (higher) levels of worker productivity. At least, this is true under conditions of perfect labor mobility.

\footnotetext{
${ }^{6}$ In an alternative specification we used earnings per worker, but the results were generally less satisfactory. In part this may be related to aggregating the earnings functions across all members of the county as opposed to using individual-level data. We also used BEA regions in alternative specifications, but this yielded poor results.
} 


\subsection{Data Sources}

Per capita income is obtained from the Burro of Economic Analysis-Regional Economic Information System and is measured in 2000. To reduce potential endogeneity bias (communities with higher income levels have higher educational attainment and vice versa), we use a 10-year lag period between income per capita (2000) and the regressors (measured in or around 1990). Human capital is measured as the percent of population aged 25 and older with at least a high school degree and is taken from the U.S. decennial Census of Population. ${ }^{7}$ Our returns to education thus reflect the returns to a high school or higher degree - the reference category is those without a high school diploma. Age is also taken from decennial Census data, and we enter this variable in linear and squared forms to allow for diminishing returns to experience. Our social capital index is a composite measure that includes data on membership associations, voting records, the county-level response rate to the Census, and the number of tax-exempt non-profit organizations from the National Center for Charitable Statistics that were compiled from a number of sources, including County Business Patterns. This index is described in more detail in Rupasingha, Goetz and Freshwater (2003). The pupil-teacher ratio is for the 1989-90 school year, and it was calculated using data from the National Center for Education Statistics (NCES). ${ }^{8}$

Private and public sector jobs as a share of all jobs are from the REIS, while population density was constructed for each county from Census data. The amenities measure was obtained from McGranahan (1999) and reflects various climate variables, topography, and bodies of waters. Summary statistics for the variables are reported in Table 1.

\section{TABLE 1}

Descriptive Statistics

\begin{tabular}{llrrrc}
\hline \multicolumn{1}{c}{ Variable } & \multicolumn{1}{c}{ Description and unit } & Mean & Std. Dev. & Minimum & Maximum \\
\hline rinc00 & Real per capita income, 2000 & 22,689 & 5,671 & 6,606 & 90,901 \\
chginc00 & Per capita income growth rate, 1990-2000 & 0.13 & 0.11 & -0.48 & 1.17 \\
educ90 & Population w/ HS degree +, 1990, \% & 69.55 & 10.34 & 31.56 & 95.54 \\
medage90 & Median age of population, 1990, years & 34.42 & 3.59 & 20.00 & 55.40 \\
Hwydum & Highway access (Yes = 1, No = 0), 1990 & 0.43 & 0.49 & 0.00 & 1.00 \\
& & $9.3 \mathrm{E}-$ & & & \\
ski90 & Social capital level, index, 1990 & 05 & 1.34 & -4.24 & 7.96 \\
ptrate89 & Pupil-teacher ratio, 1989-1990 & 16.12 & 2.73 & 4.50 & 26.68 \\
pvtemp90 & Private jobs out of total, 1990 & 72.05 & 12.20 & 8.50 & 93.32 \\
gvtemp90 & Public jobs out of total, 1990 & 16.93 & 6.91 & 4.01 & 91.42 \\
hitek90 & High-tech establishments per 10,000, 1990 & 14.68 & 96.26 & 0.00 & 3,873 \\
popden90 & Population per square mile, 1990 & 197.16 & 1,402 & 0.20 & 52,378 \\
Amnscale & Amenity scale, various years (see text) & 0.05 & 2.29 & -6.40 & 11.17 \\
\hline
\end{tabular}

\footnotetext{
${ }^{7}$ In our earlier work (Goetz and Rupasingha 2003), we used high school graduates and college graduates (or more years of education) as separate variables. This caused problems with the pupilteacher ratio in the present study.

${ }^{8} \mathrm{We}$ also used educational spending per pupil, but this is multicollinear with class size (the pupilteacher ratio).
} 


\subsection{Regression Model}

The functional form estimated, with $i$ indexing each county and $y$ denoting per capita income, is:

$$
\begin{aligned}
y_{i, 10}=\alpha & +\beta_{1} \text { Edu }_{i}+\beta_{2} \text { Age }_{i}+\beta_{3} \text { Age }_{i}^{2}+\beta_{4} \text { HiWay }_{i}+\beta_{5} \text { SKI }_{i}+\beta_{6} \text { PTR }_{i}+\beta_{7} \text { Priv }_{i} \\
& +\beta_{8} \text { Publ }_{i}+\beta_{9} \text { HiTec }_{i}+\beta_{10} \text { PopDen }_{i}+\beta_{11} \text { Amen }_{i}+e_{i}
\end{aligned}
$$

(See Table 1 for an explanation of the variable names.) The dependent variable is measured alternatively as the per capita income (level) in 2000 and as the rate of income growth between 1990 and 2000. All regressors are measured in 1990 except where indicated. We use conventional procedures, which have been well documented in the literature, to correct for spatial dependence bias and to test for dependence in the dependent variable, among the regressors, and both forms of dependence. The spatial weights matrix measures contiguity among counties.

\subsection{Spatial Effects}

Recent studies of income growth using state- and county-level data for the U.S. find statistical evidence of spatial dependence (Rey and Montouri 1999; Rupasingha, Goetz, and Freshwater 2002). Classical spatial econometric studies show that the presence of spatial dependence can lead to model misspecification that may result in biased and inconsistent OLS estimates (see Anselin 1988). Our initial exploratory investigation using county maps revealed that county-level income data for 2000 and the real per capita income growth from 1990-2000 show a pattern of spatial clustering. A subsequent quantification of spatial association using a global Moran's $I$ indicated that highly significant Moran values ( 0.472 and 0.298 , respectively, for levels of income for 2000 and income growth between 1990-2000). We employ several spatial models to account for spatial effects in the data and follow the procedures described in LeSage (1999) to select the most suitable model for each specification. The general spatial model can be written as follows.

$$
\begin{aligned}
& y=\rho W(y)+X \beta+u \\
& u=\lambda W u+\varepsilon \\
& \varepsilon \sim N\left(0, \sigma^{2} I_{n}\right)
\end{aligned}
$$

where $y$ is the dependent variable and $X$ the vector of regressors; $W$ is a weights matrix reflecting either contiguity among counties or inverse distances between counties as measures of association; $u$ and $\varepsilon$ are error terms; and $\rho$ and $\lambda$ are the spatial autoregressive parameter and the scalar spatial error coefficient, respectively. 


\section{RESULTS}

\subsection{Basic Regressions}

Table 2 presents the results of our basic equation, using both OLS and a spatial correction as well as separate equations for rural and urban areas. Both $\rho$ and $\lambda$ are statistically different from zero in the full model, indicating the presence of a spatial process not only in the dependent variable but also in the error term. A statistically significant parameter $\rho$ means that higher incomes in one county are associated with higher incomes in adjacent counties. A statistically significant $\lambda$ coefficient means that a random shock that affects income or income growth in a particular county can trigger a change in income not only in that county but also in its neighboring counties.

Counties with higher levels of educational attainment, interstate highway access, levels of social capital, private employment per capita, high-tech employment, and population density in 1990 had statistically higher incomes in 2000, as expected. Conversely, counties with larger average classroom sizes in 1989-1990 had smaller incomes per capita in 2000. This suggests that the average student "produced" in counties with larger classrooms could expect to earn a lower income 10 years later if he or she chose to remain in the same county. As expected, average age of the population has the effect of first increasing and then reducing per capita incomes, all else equal. On the other hand, public sector employment per capita and the amenity scale had no statistically significant effect on incomes.

TABLE 2

Lag Model Estimation for All Counties, Rural and Urban Areas

\begin{tabular}{|c|c|c|c|c|c|c|c|c|}
\hline \multirow[b]{2}{*}{ Variable } & \multicolumn{2}{|c|}{$\underline{\text { Full Model - OLS }}$} & \multicolumn{2}{|c|}{ Full Model - SAC } & \multicolumn{2}{|c|}{$\underline{\text { Rural Model - SAC }}$} & \multicolumn{2}{|c|}{$\frac{\text { Urban Model - }}{\text { SAC }}$} \\
\hline & Coefficient & Prob. $^{*}$ & Coefficient & Prob. & Coefficient & Prob. & Coefficient & Prob. \\
\hline Constant & $-20,838$ & 0.000 & $-21,274$ & 0.000 & $-9,022$ & 0.000 & $-56,187$ & 0.000 \\
\hline educ90 & 253.87 & 0.000 & 199.29 & 0.000 & 127.87 & 0.000 & 412.73 & 0.000 \\
\hline medage 90 & 988.88 & 0.000 & 825.59 & 0.000 & 791.66 & 0.000 & 2105.84 & 0.000 \\
\hline agesq90 & -13.31 & 0.000 & -11.05 & 0.000 & -10.83 & 0.000 & -25.95 & 0.000 \\
\hline Hwydum & 726.19 & 0.000 & 509.47 & 0.001 & -77.16 & 0.593 & -118.99 & 0.757 \\
\hline ski90 & 218.82 & 0.023 & 296.99 & 0.000 & 551.24 & 0.000 & 163.54 & 0.385 \\
\hline ptrate 89 & -123.61 & 0.001 & -115.41 & 0.000 & -134.54 & 0.000 & -304.43 & 0.000 \\
\hline pvtemp90 & 132.79 & 0.000 & 122.94 & 0.000 & 67.50 & 0.000 & 107.18 & 0.002 \\
\hline gvtemp90 & -24.35 & 0.227 & -4.14 & 0.765 & -54.65 & 0.000 & 13.42 & 0.756 \\
\hline hitek90 & 11.34 & 0.070 & 9.91 & 0.000 & 144.34 & 0.000 & 8.00 & 0.000 \\
\hline popden 90 & 0.67 & 0.010 & 0.50 & 0.000 & 12.69 & 0.000 & 0.52 & 0.000 \\
\hline Amnscale & -36.22 & 0.487 & 6.07 & 0.856 & 66.20 & 0.058 & 149.81 & 0.062 \\
\hline Rho & & & 0.33 & 0.000 & 0.23 & 0.000 & 0.27 & 0.000 \\
\hline Lambda & & & 0.04 & 0.000 & 0.08 & 0.000 & 0.02 & 0.305 \\
\hline Adjusted $\mathrm{R}^{2}$ & 0.54 & & 0.60 & & 0.49 & & 0.63 & \\
\hline Sample size & 3,035 & & 3,035 & & 2,244 & & 791 & \\
\hline
\end{tabular}


A comparison of the OLS and the spatially-corrected results suggests that the OLS model overestimates the effects of educational attainment (by 28 percent), age, pupilteacher ratio, highway access, private employment per capita, high-tech establishments, and population density. In contrast, OLS underestimates the effects of social capital levels on per capita income by 36 percent (comparing 296.99 with 218.82) relative to the spatially corrected model.

The coefficient estimates in Table 2 allow us to compare the relative impacts (or elasticities, if appropriately manipulated) of different variables on incomes per capita. For example, increasing the population with a high school degree or more by one percentage point raises per capita income in the average county by $\$ 199$, according to the full model. Increasing the social capital level by one unit is predicted to increase income by $\$ 297$. Adding one person per square mile increases income per capita by 50 cents. Having an interstate highway access ramp has the same value as reducing the average classroom size (pupil-teacher ratio) by about four students - from the sample average of 16 to 12 students. This does not mean that counties face a trade-off between building interstate access ramps and classrooms. Instead, it means that rural areas have an additional disadvantage because they have less access to interstates, holding constant the population density. Conversely, increasing the average classroom size by two pupils has about the same effect on per capita income as reducing the population with a high school degree or more by one percentage point.

Also included in Table 2 are separate regression results for rural and urban areas. The coefficient estimate for educational attainment is substantially larger in urban than in rural areas (more than twice as large). The effect of classroom size on per capita income is also stronger in urban than in rural areas, suggesting that the negative effect of larger classrooms in rural schools on later earnings is less severe in rural than in urban areas. Public sector employment, which includes school teachers who in many depressed rural areas make up the largest employment group overall, is negative and highly significant statistically in rural areas. No such effect is detected in the urban counties. The value of an additional high-tech establishment in raising per capita income is much larger in rural than in urban areas, but of course there are fewer such establishments in rural areas.

\subsection{Interactions and Externalities}

Important clues about the causes of different returns to education in rural and urban areas can be obtained by interacting educational attainment with the other regressors in equation (1). Interaction terms allow us to examine the effect of different variables on per capita incomes through the education variable in the form of externalities or spillovers. For example, according to the full model in Table 3, population density enhances the positive effect of educational attainment on per capita incomes:

$$
\partial y / \partial E d u=187.3+0.11 \text { PopDen }
$$


Similarly, we have:

$$
\partial y / \partial P o p D e n=-6.94+0.11 E d u
$$

In this case the coefficient estimate on PopDen (-6.94) becomes negative (compared to +0.50 in the model estimated without an interaction term), but the effect of education is to counteract this negative effect of population density. Since rural areas have lower average population densities than urban areas, this interaction effect is one key explanation of why returns to education are lower in rural when compared to urban areas.

Interstate highway access ramps also interact strongly and positively with educational attainment, perhaps by reducing workers' commuting costs. Since rural areas have fewer such ramps, they are again at a relative disadvantage to urban areas, all else equal. Social capital has the same effect, but in this case levels of the variable are higher in rural than in urban areas. However, this difference is not large enough to offset the disadvantages created by interactions with respect to the other variables. Likewise, private sector jobs, high-tech establishments and amenities interact positively with educational attainment, while age has a negative interaction.

In terms of the pupil-teacher ratio, the interaction effect is positive (7.25) and statistically significant according to Table 3 . The non-interacted term for the pupil-teacher ratio remains negative. This result indicates that the positive effect of educational attainment on income (unexpectedly) increases with larger classroom sizes:

$$
\partial y / \partial E d u=80.9+7.25 P T R
$$

Holding constant classroom size, higher educational attainment increases income levels per capita, offsetting the negative effect of higher classroom size, as indicated by:

$\partial y / \partial P T R=-633.1+7.25 E d u$. Solving the latter equation for $\partial y / \partial P T R=0$ yields $E d u^{*}=$ 87.3. In other words, 87.3 percent of the population needs to have a high school degree or higher to offset the negative effect of greater classroom size (at the mean size) on per capita income levels.

\section{TABLE 3}

Determinants of Returns to Education: Interactions Effects

\begin{tabular}{lcccc}
\hline & \multicolumn{2}{c}{ Full Model } & \multicolumn{2}{c}{ Rural Model } \\
Interaction term & Coefficient & Probability & Coefficient & Probability \\
\hline education * median age & -3.41 & 0.007 & -2.52 & 0.037 \\
education * access to a highway & 118.5 & 0.000 & 9.24 & 0.515 \\
education * social capital index & 10.11 & 0.048 & 7.46 & 0.119 \\
education * pupil-teacher ratio & 7.25 & 0.002 & 2.74 & 0.237 \\
\hline
\end{tabular}


Table 3 also shows the effects of interactions in rural areas. In particular, private jobs, amenities, and high-tech establishments each enhance the positive effect of educational attainment on per capita incomes. In contrast, population density, social capital, classroom size, and highway access ramps do not enhance or reduce the effect of education in a statistically significant manner.

We thus conclude that rural areas not only have a disadvantage in terms of returns to education because population densities are lower than in urban areas, but rural areas also would not benefit on this count in terms of the interaction effect if they could somehow raise population density. Benefits of higher population density might be achieved, or simulated, for example, through access to and greater use of the Internet and information technology generally. (See also the discussion in Anselmo-de Castro and Jensen-Butler 2003.) To illustrate further, the same is true of highway access ramps in rural areas. Rural areas do benefit from such ramps in terms of higher incomes, but they do not obtain the additional boost in the form of a spillover through higher returns from educational attainment that goes along with having such a ramp in urban areas (or in the full model).

\subsection{Estimates by Region}

The estimates by region in Table 4.1 suggest that the independent effect of educational attainment on per capita incomes is strongest in the West (an additional \$337.81 of income per capita for each one percentage point increase in the population with a high school degree) and weakest in the Midwest region. Experience of the population, as reflected in age, is statistically insignificant in the Northeast and Midwest regions, perhaps reflecting demographic particularities in these more mature regions. Highway access is statistically significant only in the Northcentral region, which also shows the strongest effect for social capital levels. In the West, this social capital effect is not distinguishable from zero at the 10 percent level of significance. Amenities and the pupil teacher ratio are not significant statistically in any of the regions in this formulation, while high-tech establishments have no effect in the West.

In comparison, the regional estimations only for rural counties provide some interesting differences relative to the regional models (Table 4.2). In particular, while the effect of educational attainment remains otherwise comparable, the returns to education in the rural Northeast are lower than in the rural South (the opposite was true for all counties in Table 4), and they are less than half of the returns in the rural West. The effect of age is highly significant in each of the rural regions other than the Northeast, while the interstate highway access variable is statistically significant only in the rural South, where the effect is negative. The effect of social capital levels is highest in the rural Northeast and non-existent in the rural West. Classroom size has the expected negative effect in all cases where it is statistically significant (rural South and West). Finally, the presence of high-tech establishments is positive and different from zero in each of the rural regions. 
TABLE 4.1

Lag Model Estimation for Regions

\begin{tabular}{|c|c|c|c|c|c|c|c|c|}
\hline \multirow[b]{3}{*}{ Variable } & \multicolumn{4}{|c|}{ Northeast - SAR } & \multirow{2}{*}{\multicolumn{2}{|c|}{ Northcentral - SAR }} & \multirow{2}{*}{\multicolumn{2}{|c|}{ West - SAR }} \\
\hline & Mode & & $\underline{\text { South - SA }}$ & Model & & & & \\
\hline & Coefficient & Prob. & Coefficient & Prob. & Coefficient & Prob. & Coefficient & Prob. \\
\hline Constant & $-73,324$ & 0.065 & $-11,306$ & 0.000 & $-13,811$ & 0.002 & $-55,522$ & 0.000 \\
\hline educ90 & 308.65 & 0.000 & 241.90 & 0.000 & 209.12 & 0.000 & 337.81 & 0.000 \\
\hline medage 90 & 2,528 & 0.247 & 417.74 & 0.000 & 302.01 & 0.121 & $2,108.40$ & 0.000 \\
\hline agesq90 & -32.95 & 0.298 & -5.71 & 0.000 & -3.94 & 0.119 & -28.35 & 0.001 \\
\hline Hwydum & -205.77 & 0.671 & 12.09 & 0.950 & 785.36 & 0.000 & 519.34 & 0.268 \\
\hline ski90 & 663.39 & 0.013 & 586.01 & 0.000 & 724.94 & 0.000 & 378.61 & 0.116 \\
\hline ptrate 89 & -101.06 & 0.479 & -5.77 & 0.896 & 67.33 & 0.128 & -48.18 & 0.538 \\
\hline pvtemp90 & 198.83 & 0.003 & 68.91 & 0.000 & 68.25 & 0.000 & 120.52 & 0.000 \\
\hline gvtemp90 & 203.83 & 0.015 & -41.33 & 0.028 & -31.51 & 0.101 & -49.55 & 0.220 \\
\hline hitek90 & 36.14 & 0.000 & 10.07 & 0.000 & & 0.000 & 0.43 & 0.740 \\
\hline popden 90 & 0.06 & 0.410 & 2.45 & 0.000 & 0.22 & 0.522 & 5.75 & 0.000 \\
\hline Amnscale & 35.48 & 0.877 & -21.22 & 0.760 & -3.95 & 0.954 & 119.62 & 0.295 \\
\hline Rho & 0.38 & 0.000 & 0.28 & 0.000 & 0.40 & 0.000 & 0.27 & 0.000 \\
\hline Lambda & & & 0.06 & 0.000 & & & & \\
\hline Adjusted R & 0.81 & & 0.61 & & 0.51 & & 0.56 & \\
\hline Sample size & 299 & & 1,274 & & 1,053 & & 409 & \\
\hline
\end{tabular}

TABLE 4.2

Lag Model Estimation for Regions - Rural Counties Only

\begin{tabular}{|c|c|c|c|c|c|c|c|c|}
\hline \multirow[b]{2}{*}{ Variable } & \multicolumn{2}{|c|}{ Northeast - SAR } & \multicolumn{2}{|c|}{ South - SAC Model } & \multicolumn{2}{|c|}{ Northcentral - SAC } & \multicolumn{2}{|c|}{ West - OLS } \\
\hline & Coefficient & Prob. & Coefficient & Prob. & $\overline{\text { Coefficient }}$ & Prob. & Coefficient & Prob. \\
\hline Constant & $-18,900$ & 0.596 & $-4,798$ & 0.005 & $-14,858$ & 0.000 & $-31,923$ & 0.000 \\
\hline educ90 & 137.11 & 0.002 & 167.26 & 0.000 & 120.09 & 0.000 & 292.17 & 0.000 \\
\hline medage 90 & 285.13 & 0.886 & 542.14 & 0.000 & 831.35 & 0.000 & 1540.1 & 0.001 \\
\hline agesq90 & -2.36 & 0.934 & -7.94 & 0.000 & -11.06 & 0.000 & -20.50 & 0.004 \\
\hline Hwydum & -298.40 & 0.487 & -398.66 & 0.056 & 312.62 & 0.130 & 27.64 & 0.945 \\
\hline ski90 & $1,102.1$ & 0.000 & 555.64 & 0.000 & 866.78 & 0.000 & 39.26 & 0.881 \\
\hline ptrate89 & 222.46 & 0.156 & -97.03 & 0.045 & 1.65 & 0.975 & -238.35 & 0.010 \\
\hline pvtemp 90 & 160.93 & 0.003 & 32.16 & 0.012 & 44.01 & 0.000 & 113.07 & 0.000 \\
\hline gvtemp90 & 128.17 & 0.067 & -86.34 & 0.000 & -7.12 & 0.713 & -80.70 & 0.060 \\
\hline hitek90 & 170.39 & 0.000 & 156.25 & 0.029 & 149.79 & 0.011 & 131.01 & 0.027 \\
\hline popden 90 & 8.45 & 0.005 & 17.38 & 0.000 & 10.70 & 0.010 & 17.14 & 0.068 \\
\hline Amnscale & 217.65 & 0.342 & 151.73 & 0.044 & -102.71 & 0.159 & 28.24 & 0.795 \\
\hline Rho & 0.23 & 0.007 & 0.30 & 0.000 & 0.37 & 0.000 & & \\
\hline Lambda & & & 0.04 & 0.013 & 0.02 & 0.005 & & \\
\hline adjusted $\mathrm{R}^{2}$ & 0.69 & & 0.46 & & 0.47 & & 0.44 & \\
\hline Sample size & 299 & & 1,274 & & 1,053 & & 409 & \\
\hline
\end{tabular}

\section{CONCLUSION}

Our analysis lays some of the groundwork needed to design policies that enhance the returns on the investments made by regions in public education. A general conclusion from this analysis is that it is more difficult for rural areas to "offer" high returns to a high school degree than urban areas, and perhaps returns that are commensurate with the private costs of the investment in a higher degree. This is true after we control for a host 
of other factors influencing the returns to education. Our analysis reveals that failure to control for spatial dependence bias in this kind of work leads to overestimates of the returns to human capital and to underestimates of the returns to social capital, as we have defined these measures. Our results also show the trade-offs among different regressors in terms of raising income levels per capita.

Finally, our analysis involving interaction terms systematically sheds light on the reasons for the lower observed returns to educational attainment in rural areas. In particular, this part of the study revealed that while higher population density and interstate highway access are associated with higher incomes in rural areas, these areas are disadvantaged by two factors. First, they have lower density and numbers of access ramps to begin with; and second, they do not benefit from the additional positive interaction between these variables and educational attainment. This tends to further increase the gap between the returns to education in urban and rural areas.

\section{REFERENCES}

Anselin L., 1988. Spatial Econometrics: Methods and Models. Kluwer Academic Publishers: Dordrecht.

Anselmo de Castro, E. and C. Jensen-Butler, 2003. "Demand for Information and Communication Technology-Based Services and Regional Economic Development," Papers in Regional Science 82, 27-50.

Barro, R., 1991. "Economic Growth in a Cross-Section of Countries," Quarterly Journal of Economics 106, 407-43.

Beaulieu, L.J. and M. Barfield, 2000. Human Capital Endowments and Labor Force Experiences of Southerners: A Ten-Year Perspective. TVA Rural Studies.

Becker, G.S., 1964. Human Capital. Columbia University Press: New York.

Beeson, P. and D. Dejong, 2002. "Divergence," Contributions to Macroeconomics 2, 1, 2002, article 6 available at http://www.bepress.com/bejm accessed May 3, 2004.

Cheeseman-Day, J. and E.C. Newburger, 2002. The Big Payoff: Educational Attainment and Synthetic Estimates of Work-Life Earnings. Current Population Reports, Special Studies, P23-210.

Ciccone A. and R.E. Hall, 1996. "Productivity and the Density of Economic Activity," American Economic Review 68, 54-70.

Dev Bhata, S. and J. Lobo, 2000. "Human Capital and Per Capita Product: A Comparison of U.S. States," Papers in Regional Science 79, 393-411.

DeVol, R.C., 1999. America's High-Tech Economy: Growth, Development, and Risks for Metropolitan Areas. The Milken Institute: Santa Monica, CA.

Glaeser, E.L., 1994. "Why Does Schooling Generate Economic Growth?" Economics Letters 44, 333-337.

Goetz, S.J., D.L. Debertin, and A. Pagoulatos, 1998. "Human Capital, Income, and Environmental Quality: A State-Level Analysis," Agricultural and Resource Economics Review 28(2), 200-208.

Goetz, S.J. and D. Hu, 1996. "Economic Growth and Human Capital Accumulation: Simultaneity and Expanded Convergence Tests," Economics Letters 51, 355-62. 
Goetz, S.J. and A. Rupasingha, 2003. "The Returns to Higher Education: Estimates for the Contiguous States," Economic Development Quarterly 17(4), 337-351.

Goldin, C. and L.F. Katz, 1999. "The Returns to Skill across the Twentieth Century United States," National Bureau of Economic Research, Inc., NBER Working Paper No. 7126.

Krueger, A.B., 1999. "Experimental Estimates of Education Production Functions," Quarterly Journal of Economics 114(2), 497-532.

Krueger, A.B. and M. Lindahl, 2001. "Education for Growth: Why and For Whom?" Journal of Economic Literature 39, 1101-36.

LeSage J.P., 1999.Spatial Econometrics.Available at http://www.rri.wvu.edu/ WebBook/LeSage/ spatial/spatial.html.

Levine, R. and D. Renelt, 1992. "A Sensitivity Analysis of Cross-Country Growth Regressions," American Economic Review 82, 942-63.

Lucas, R., 1988. "On the Mechanics of Economic Development," Journal of Monetary Economics 22L1, 3-42.

McGranahan, D.A., 1999. Natural Amenities Drive Population Change. USDA Economic Research Service AER-781.

Mincer, J., 1974. Schooling, Earnings, and Experience. Columbia Univ. Press: New York.

Nelson, J.R. and R. Julia-Wise, 1999. Higher Education and the Labor Market in the State of Idaho. University of Idaho Dept. of Agricultural Economics and Rural Sociology, Agricultural Economics Research Series No. 99-01.

Ngarambé, O., S.J. Goetz, and D.L. Debertin, 1998. "Regional Economic Growth and Income Distribution: County-Level Evidence from the U.S. South," Journal of Agricultural and Applied Economics 30, 325-337.

Okamoto, L., "Vilsack Plans Tax Credit to Curb 'Brain Drain'," Des Moines Register, $10 / 10 / 2001$.

Pennsylvania State Data Center, 1999. Data Center Profiles "Hot" Topics in Pennsylvania. PSDC Research Brief. Available at pasdc.hbg.psu.edu/pasdc/briefs/brief587. html. Accessed on 06/30/2001.

Power, T.M. and R. Barrett, 2001. Post-Cowboy Economics: Pay and Prosperity in the New West. Island Press: Washington, D.C.

Rappaport, J., 1999. "Local Growth Empirics," Center for International Development, Harvard University, CID Working Paper No. 23.

Rappaport, J. and J. Sachs, 2001. "The U.S. as a Coastal Nation," Federal Reserve Bank of Kansas City, RWP 01-11. http://www.kc.frb.org/publicat/reswkpap/rwp01-11.htm

Rauch, J.E. 1993. "Productivity Gains from Geographic Concentration of Human Capital: Evidence from the Cities," Journal of Urban Economics 34, 380-400.

Rey, S.J. and B.D. Montouri, 1999. "U.S. Regional Income Convergence: A Spatial Econometric Perspective," Regional Studies 33, 143-156.

Rupasingha, A., S.J. Goetz, and D. Freshwater, 2000. "Social Capital and Economic Growth: A County-Level Analysis," Journal of Agricultural and Applied Economics $32,565-572$.

, 2002. "Social and Institutional Factors as Determinants of Economic Growth: Evidence from the United States Counties," Papers in Regional Science 81, 139-155. 
, 2005. "The Production of Social Capital in Rural Counties," forthcoming, Journal of Social Economics.

Sianesi, B. and J. Van Reenen, 2002. The Returns to Education: A Review of the Empirical Macro-Economic Literature. The Institute for Fiscal Studies, WP02/05, March.

Simon, C.J. and C. Nardinelli, 2002. "Human Capital and the Rise of American Cities," Regional Science and Urban Economics 32, 59-96.

Spence, M.A. 1973. "Job Market Signaling," Quarterly Journal of Economics 87(3), 355-74.

Summers, A.A. and B.L. Wolfe, 1977. "Do Schools Make a Difference?" American Economic Review 67(4), 639-52.

Trostel, P.A., 2002. "Workforce Development in Maine: Held Back by the Lack of Higher Education," University of Maine Department of Economics and Margaret Chase Smith Center for Public Policy. 